\title{
Editorial
}

Andrey N. Zagoruiko

\section{Chemical engineering research in Russia: national trends within the global context}

https://doi.org/10.1515/revce-2020-0096

The history of chemical engineering research in Russia goes back to the 18th century, starting with the works of Mikhailo Lomonosov, who made a great contribution to the development of Russian and European science, including chemistry and chemical technology. In the 19th century, Lomonosov's works were followed by excellent chemists and chemical engineers like Nikolay Zinin, Alexander Butlerov, and many others. The first educational course on chemical technology was introduced into Moscow State University as early as 1807.

A few bright examples of the successful developments shall be mentioned. Russian engineers Vladimir Shukhov and Alexander Bari with active participation of Dmitry Mendeleev, who is widely known for his discovery of the periodic law, have developed the first oil cracking process in world history. Their plant was set into operation in 1881 thus marking the beginning of the global transfer from coal-based energy to one driven by products of oil processing. In the first quarter of the 20th century, Sergey Lebedev managed to develop and construct the whole self-sufficient synthetic rubber industry in Soviet Russia; this was done under extremely complicated conditions, during an economy which was practically ruined during the brutal civil war. The works of another great Russian chemist and chemical engineer, Vladimir Ipatieff, on highpressure catalytic reactions started in Russia and accomplished in the USA, have formed the world basis for the modern catalytic technologies in oil processing and petrochemistry.

The chemical industry in the USSR was growing fast after World War II, this was accompanied by an active development of research in chemical engineering. A significant success in the development of domestic technologies was achieved in the nitrogen industry (manufacturing of ammonia and nitric acid), production of sulfuric acid, vinyl

Andrey N. Zagoruiko, Boreskov Institute of Catalysis, pr. Lavrentieva 5, Novosibirsk 630090, Russia, E-mail: zagor@catalysis.ru.

https://orcid.org/0000-0001-6217-0302 chloride, natural gas and oil processing, and many others areas.

The current Russian research in chemical engineering follows these great traditions. The modern scientific investigations include a wide range of various subject areas: multiscale reaction engineering, heat and mass transfer intensification, purposeful application of unsteady-state and dynamic approaches for scientific and practical purposes, process modeling and simulation, and application of new research methods. The selection of scientific topics is to some extent defined by the specific practical tasks, formulated by domestic industries, but in general, it is completely within the global developmental context of chemical engineering science.

This special issue is dedicated to current chemical engineering studies in Russia. It follows the concept of a similar special issue dedicated to Chinese research in this area published earlier in Reviews in Chemical Engineering (vol. 35, issue 8, 2019 and vol. 36, issue 1, 2020).

The geography of Russian chemical engineering science is rather wide, the research is performed in many regions of Russia, starting from historical scientific centers in Moscow and Saint Petersburg up to Academic Town in Novosibirsk, which is now considered the informal "scientific capital" of the Russian Federation.

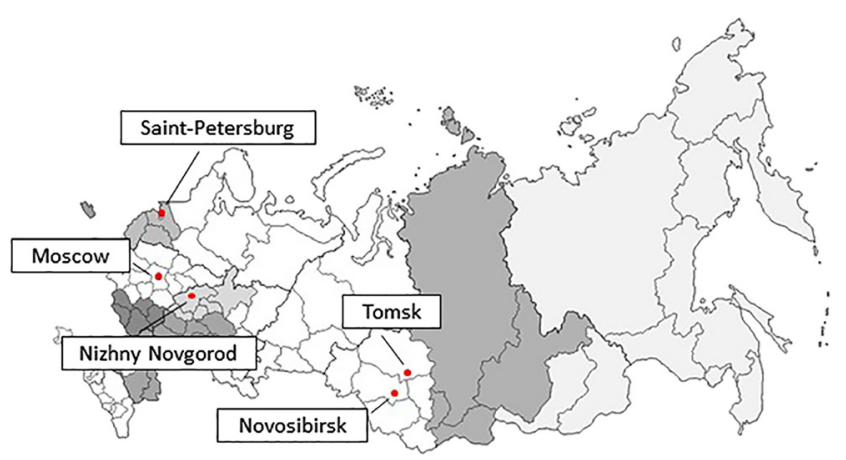

A map of Russian research sites that contributed to this special issue.

This special issue does not pretend to cover all Russian research works in chemical engineering and related areas. Its target is to give the general scope of 
current trends and promising research directions in this area that are of global interest.

I would like to express my sincere gratitude to Prof. Dan Luss who proposed the idea of such a special issue and invited me to become its guest editor, and to Prof. Neima Brauner and Dr. Gunda Stöber who greatly organized the whole reviewing and editing process. 